\title{
Urban Women Farmers' Involvement in Cassava Tuber Processing in Imo State, Nigeria
}

\author{
${ }^{1}$ Nwakwasi R.N., P.C.Umunakwe ${ }^{1}$, M.N. Okeke ${ }^{2}$, E.O.Onwuma ${ }^{1}$ and S. Nwaozuzu ${ }^{1}$ \\ ${ }^{I}$ Department of Agricultural Extension, Federal University of Technology, P.M.B. 1526, Owerri, \\ Nigeria. \\ ${ }^{2}$ Chukwuemeka Odumegwu Ojukwu University, Igbariam Campus (COOU), Anambra State, Nigeria.
} Received: 15 August 2020 / Accepted 30 Oct. 2020 / Publication date: 20 Nov. 2020

\begin{abstract}
The rising popularity of cassava as a staple crop has raised its acceptance and cultivation among many households in sub-Saharan Africa. The study investigated the roles urban women played in cassava processing in Imo State, Nigeria. Multistage sampling procedure was used to select a sample of 100 rural women farmers. Data were collected from the respondents using interview schedule. Data were analysed using percentage and mean statistic. The major cassava products available in the area included fufu $(91.7 \%)$, garri $(90.5 \%)$, cassava balls $(70 \%)$ and abacha/tapioca $(65.2 \%)$. The roles they played included pounding $(98.0 \%)$, peeling $(97.8 \%)$, frying $(97.0 \%)$, cooking $(96.7 \%)$, sifting $(95.0 \%)$ and boiling $(95.0 \%)$. The constraints faced by the women included poor market demand $(\bar{X}=3.5)$, unstable power supply $(\bar{X}=3.4)$, inadequate information on processing $(\bar{X}=3.3)$, the long period of time spent on processing $(\bar{X}=3.4)$ and inadequate finance $(\bar{X}=3.3)$. It was recommended that credit facilities among other things should be provided to the women to increase their involvement in cassava processing.
\end{abstract}

Keywords: Cassava processing, urban farmers, women involvement, cassava products, processing constraints, Nigeria

\section{Introduction}

Cassava (Manihot esculenta Crantz) is a tropical root crop, originally from Amazonia, that provides the staple food of an estimated 800 million people worldwide. Grown almost exclusively by low-income smallholders, it is one of the few staple crops that can be produced efficiently on a smallscale without the need for mechanization or purchased inputs and in marginal areas with poor soils and unpredictable rainfall (Food and Agriculture Organization, FAO, 2013). In sub-Saharan Africa (SSA) it is grown mainly by small-holder farmers often on marginal lands where it is productive even on poor soils and under drought conditions (Naziri et al., 2014). This has made it a vital crop for both food security and income generation in developing countries. The International Fund for Agricultural Development (IFAD) and Food and Agricultural Organization (FAO) (2000) reported that cassava has historically played an important famine-prevention role in Eastern and Southern Africa where maize is the preferred food staple and drought is a recurrent problem.

Africa is the largest cassava producing region in the world and Nigeria is the world's leading producer, accounting for about 55\% of world's production (James \& Faleye, 2015). The sub-Saharan African region is one of the most producing region in Africa. It produced about 80.9 million metric tons of cassava in 2012, accounting for $54.2 \%$ of African global production. Nigeria alone produced 2016 about 4,548 million tons in 2016 (FAO, 2017). Although cultivated mostly in rural areas especially in developing countries, the rising importance of urban farming has seen many urban dwellers cultivating cassava. According to FAO (2013) this resulted from the rising urban poverty and hike in the cost of cereals which has led to intensification in the production and consumption of cassava so as to boost urban food security in Africa.

Cassava utilization patterns vary considerably globally. In Africa, much of the cassava tubers produced ( $88 \%$ ) is used for human food, with over $50 \%$ used in the form of processed products (Westby, 2002). They are consumed as fresh roots (which may be eaten raw, roasted in open fire or boiled in water or oil), dried roots (which are stored or marketed as chips, balls and flour), pasty products

Corresponding Author: Iwuagwu, E.N., Department of Agricultural Extension, Federal University of Technology, P.M.B. 1526, Owerri, Nigeria.

E-mail: polycap.umunnakwe@futo.edu.ng 
(uncooked and steamed pastes), granulated products (garri, attieke and tapioca) and cassava leaves (IFAD \& FAO, 2000). Besides, cassava tubers have many industrial uses. Echebiri and Edaba (2008) put the estimates of industrial cassava use in Nigeria as $16.0 \%$ as chips in animal feed, $5.0 \%$ processed into syrup concentrate for soft drinks and less than $1.0 \%$ processed into high quality cassava flour used in biscuit and confectionery, dextrin, adhesives, starch and hydrolysates for pharmaceuticals and seasonings.

In spite of its agronomic and economic importance, cassava production faces numerous challenges. The tubers are bulky with about $70.0 \%$ moisture content and therefore transportation of the tubers to urban markets is difficult and expensive. The roots contain cyanide which is toxic to humans and livestock; and is inedible when uncooked. The tubers have a very short shelf life ( 3 - 4 days) which renders them unpalatable and unmarketable after harvest (Reilly et al., 2007). However, several approaches have been employed to increasing the palatability of cassava tubers and curtail the postharvest losses resulting from the perishability such as underground storage, storage in boxes with moist saw dust, storage in bags combined with use of fungicides, pruning plants before harvest, cold storage and freezing or waxing the roots. But these methods are not appropriate for large volumes of cassava tubers because they are too expensive or complicated (Sanchez et al., 2016).

Processing reduces perishability and toxicity. The International Food Information Council Foundation (2010) stated that processing converts food substances into more useful, shelf-stable and palatable foods or portable beverages for human consumption. Van Boekel et al. (2010) opined that it improves quality, extends shelf life, improves bioavailability, removes harmful microbes and toxins and improves the safety of food. Nyirenda et al. (2011) stated that cassava processing improves palatability, increases shelf-life, facilitates transport and most importantly, detoxifies cassava roots by removing cyanogens.

In Nigeria, women play key roles in the production, harvesting, processing and marketing of agricultural produce. They contribute about $58.0 \%$ of the total agricultural labour in Southwest, $67.0 \%$ in the Southeast and $58.0 \%$ in the Central zones (Onyemuwa, 2012). Research focus has dwelt so much on the activities of rural farmers unlike their urban counterparts, thus creating a gap in knowledge. This study was designed to fill the gap by identifying the roles urban women farmers played in cassava processing in Imo State, Nigeria.

\section{Objectives of the study}

The main objective of the study was to identify the roles of urban women farmers in cassava processing among rural women farmers in Imo State, Nigeria. Specifically, the study sought to:

1. Describe the socioeconomic characteristics of the women farmers;

2. Identify processed cassava products in the area;

3. Ascertain the level of involvement of the women in cassava processing;

4. Determine the roles the women performed in cassava processing; and

5. Identify the constraints they faced in cassava processing in the area.

\section{Methodology}

The study was conducted in Imo State, Nigeria. It is located within longitude $5^{\circ} 29^{\prime} \mathrm{N} 5^{\circ} 58^{\prime} \mathrm{N}$ and longitude $7^{\circ} 20^{\prime} \mathrm{E} 7^{\circ} 03^{\prime} \mathrm{E}$ (en.m.wikipedia.org/wiki/Imo_State). It has boundaries with Abia State on the east, River Niger and Delta Stat to the west, Anambra State on the north and Rivers State to the south. It has a population of 4.7 million people and occupies an area of $5,530 \mathrm{Km}^{2}$. It is divided into 27 local government areas. The area has two distinct seasons - rainy which begins in March and ends in October and dry which begins in November and ends in March. The temperature of the area is usually high throughout the year with no monthly average below $70^{\circ} \mathrm{C}$ and annual range of about $50^{\circ} \mathrm{C}$. The hottest period is between January and April just before the rain sets in. Relative humidity is about $90 \%$, except in December to February when the harmattan brings in dry conditions. Rainfall is the most vital climatic factor in the area because the majority of the people depend on it for agriculture. Annual rainfall is heavy, about $2,400 \mathrm{~mm}$ in most places. Vegetation of the area is rainforest and this supports cassava production (Chikwendu et al., 2017).

The population for the study comprised all women cassava farmers living in urban areas in Imo state. Multistage sampling procedure was used to select the sample. Stage one was the purposive 
selection of five urban communities in the state. The second stage was the selection of 20 farmers who cultivate cassava.

Processed cassava products in the study area was measured by providing a list of common cassava products in Nigeria and asking them to indicate the ones available to them and their responses recorded as yes or no. The level of involvement was measured using the nominal scale of highly involved, moderately involved and not involved. The roles performed by women in cassava processing were measured by listing activities involved in cassava processing and the women were asked to indicate the ones they were involved in by ticking 'yes' or 'no'. The constraints faced by the women in cassava processing were determined by providing a list of likely constraints to cassava processing and asking the women to indicate the ones applicable to them and their responses recorded on a 3-point Likert-type scale of very serious $=3$, serious $=2$ and not serious $=1$. The mean of the scale was determined by adding the values of the scale (i.e. $3+2+1)$ and dividing by the number of scale $(6 / 3)$ to obtain the discriminating index, 2.0. So, any item with a score $\geq 2.0$ would be taken as a constraint to cassava processing in the area. Data were collected using structured questionnaire and were analyzed using mean score and percentages.

\section{Results and Discussion}

Table 1 shows that the majority (58.0\%) of the women was aged between 41 and 60 years and the mean age was 47.6 years. The majority $(51.1 \%)$ were married, the majority $(76.0 \%)$ received one form of formal education or the other; the majority $(56.0 \%)$ had farming experience of $16-25$ years and had spent an average of 12.8 years in farming. The result implies that the farmers are aging and may not efficiently engage in cassava processing especially as it is mostly done manually in many developing countries like Nigeria.

Chekene (2015) reported that farming work force in Nigeria is dominated by farmers above 40 years of age. Age could influence a farmer's ability to perform tasks requiring physical strength. It could also influence a farmers' willingness to adopt innovations as younger farmers are less conservative than aged farmers (Agbamu, 2004). Marriage encourages synergy among farm family members. This could promote the spread of innovations on cassava processing as every member of the farm family is a potential source of information. It could also encourage division of labour among the farm family members thus reducing the cost of labour and maximizing the use of time.

The acquisition of formal education could enhance decision making ability among farmers. Educated farmers can access agricultural information from an array of sources since they could read and write unlike their uneducated counterparts and this could enhance the cassava processing enterprise. The result however showed that the farmers have been into cassava production for a relatively long period of time. This period of time could provide them with a wealth of experience valuable in cassava processing. More so, the number of years they have spent in processing would have enabled them save some money that would enhance their adoption of cassava processing innovations. Oluwatosin (2011) found that access to credit reduces inefficiency as it enables farmers adopt better technologies.

The result further revealed that the majority $(60.0 \%)$ of the farmers had household sizes of $6-10$ persons with an average of eight people; the majority $(66.0 \%)$ were members of social organizations; the majority $(60.0 \%)$ had a farm size of $1-2$ hectares with a mean of 1.2 hectares; a greater proportion (47.0\%) had a monthly income of less than $\$ 20,000.00$ and a mean income of about $\$ 40,000.00$. The result also showed that inheritance $(67.0 \%)$ was the major means of access to land among the farmers.

The result implies that the study area is dominated by farmers with relatively large household sizes. Large households entail a greater number of people who are potential sources of labour and useful agricultural information. Membership of social organizations promotes diffusion of innovations and interactions among farmers and extension agents. It could also enhance cooperative activities among famers like the popular thrift societies. Also, the result reveals that the farmers are smallholders. This could be attributed to the land tenure system prevalent in Africa. According to FAO (2011) the patriarchal setting in many countries in Africa whereby male dominates on decisions concerning land makes it difficult if not impossible for women to access or own land in their own right. Small land holding could negatively influence a farmer's productivity which could impair his willingness to adopt innovations. Finally, the monthly income regime of the farmers suggests that they could afford some 
traditional implements required for cassava processing. However, this ability may be limited by demands on the income resulting from their relatively large household sizes.

Table 1: Distribution of women according to socioeconomic characteristics

\begin{tabular}{|c|c|c|}
\hline Socioeconomic characteristics & $\%$ & $\overline{\boldsymbol{X}}$ \\
\hline \multicolumn{3}{|l|}{ Age (Years) } \\
\hline $1-20$ & 2.0 & \\
\hline $21-40$ & 27.0 & \\
\hline $41-60$ & 58.0 & 47.6 \\
\hline$>60$ & 14.0 & \\
\hline \multicolumn{3}{|l|}{ Marital status } \\
\hline Single & 16.0 & \\
\hline Married & 51.0 & \\
\hline Divorced & 10.0 & \\
\hline Widowed & 23.0 & \\
\hline \multicolumn{3}{|l|}{ Level of Education } \\
\hline No formal education & 24.0 & \\
\hline Primary school & 22.0 & \\
\hline Secondary school & 33.0 & \\
\hline Tertiary Education & 21.0 & \\
\hline \multicolumn{3}{|l|}{ Experience in processing } \\
\hline$<5$ & 11.0 & \\
\hline $6-15$ & 17.0 & 12.80 \\
\hline $16-25$ & 56.0 & \\
\hline$>25$ & 16.0 & \\
\hline \multicolumn{3}{|c|}{ Household Size (Number of Persons) } \\
\hline$<5$ & 21.0 & \\
\hline $6-10$ & 60.0 & 8 \\
\hline$>10$ & 19.0 & \\
\hline \multicolumn{3}{|c|}{ Membership of social Organizations } \\
\hline Yes & 66.0 & \\
\hline No & 34.0 & \\
\hline \multicolumn{3}{|l|}{ Nature of farm Business } \\
\hline Full Time & 41.0 & \\
\hline Part Time & 59.0 & \\
\hline \multicolumn{3}{|l|}{ Farm Size (Hectares) } \\
\hline$<1$ & 20.0 & \\
\hline $1-2$ & 60.0 & 1.2 \\
\hline$>2$ & 20.0 & \\
\hline \multicolumn{3}{|l|}{ Monthly Income (A‘000) } \\
\hline$\leq 20$ & 47.0 & \\
\hline $21-40$ & 14.0 & 39.633 .1 \\
\hline $41-60$ & 19.0 & \\
\hline$>60$ & 20.0 & \\
\hline \multicolumn{3}{|l|}{ Land tenure system } \\
\hline Inherited & 76.0 & \\
\hline Purchased & 40.0 & \\
\hline Rented & 50.0 & \\
\hline Leased & 28.0 & \\
\hline
\end{tabular}

Source: Field Survey Data, 2015

\section{Processed cassava products in the area}

Figure 1 reveals that fufu (91.7\%), garri (90.5\%), cassava balls $(70.0 \%)$ and abacha/tapioca $(65.2 \%)$ were the available cassava products in the study area. This implies that cassava is 
predominantly used as human food in the area. The dominance of these products might imply cultural preference of the products since cassava is processed into different products in different locations. Westby (2002) stated that the majority $(88.0 \%)$ of cassava tubers produced in Africa is used for human food, with over $50.0 \%$ used in the form of processed products. This finding concurs with the reports of Onyemauwa (2010) and the Presidential Initiative on Cassava (2006) that garri, fufu, starch, lafun, chips and pellets constitute the primary cassava products in Nigeria. The processing of cassava into more storable forms basically offers farmers the opportunity of overcoming the perishability of the fresh roots. It could also enhance their financial returns, add value, reduce drudgery and environmental impacts.

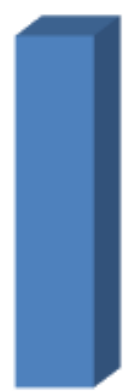

Fufu

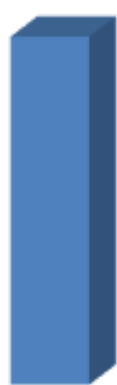

Garri

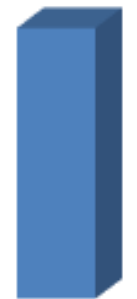

Cassava balls

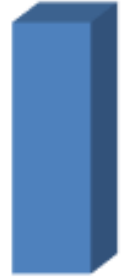

Fermented paste and starch

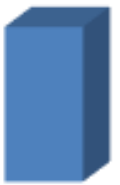

Abacha/tapioca Cassavaflour

Processed cassava products

Fig. 1: Bar chart showing available cassava products

\section{Level of involvement in cassava processing}

Figure 2 reveals that most (72.3\%) of the women were highly involved in cassava processing while $26.7 \%$ was moderately involved. The result no doubt affirms the significant role women play in agriculture in Africa. Cassava is culturally designated women's crop in Nigeria and thus its production and processing are carried out mostly by women. This may be due to cultural, social and economic factors surrounding the crop. The notion that it is women's crop might take men's attention away to other crops considered men's crops. Similarly, the consideration of the crop as more of a food crop than a cash crop might reduce men's involvement in its production. Men tend to show more interest in the production of cash crops than food crops. Okoroafor and Nwaobiala reported that women dominated cassava production and processing in Abia State, Nigeria.

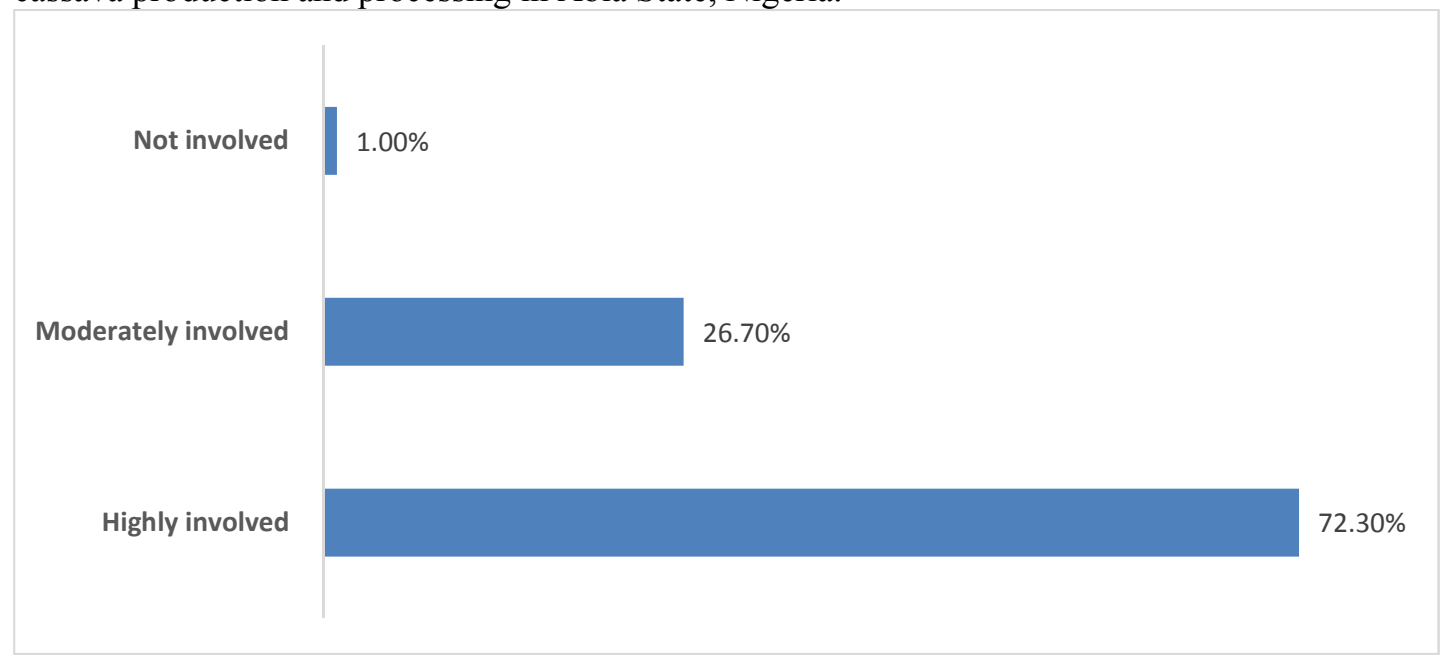

Fig. 2: Level of involvement in cassava processing 


\section{Roles performed by women in cassava processing}

Figure 3 shows that women performed many activities involved in cassava processing in the study area which include pounding $(98.1 \%)$, peeling $(97.9 \%)$, frying $(96.9 \%)$, cooking $(96.9 \%)$, sifting (95.9\%), boiling (95.1\%), soaking $(90.1 \%)$ and milling (85.1\%). However, grating $(44.2 \%)$ and pressing $(31.1 \%)$ were the least of roles performed by the women in the study area. This showcases the significant involvement of women in agro-processing. Bello et al. (2013) found that the majority $(89.9 \%)$ of the women surveyed were involved in cassava processing. The dominance of women in cassava processing could be attributed to the traditional perception of the crop as a 'woman crop' (Ani, 2004). In line with this perception, men may show no much interest in the activities involved in it from cultivation to processing. Nweke et al. (2002) reported that women perform most of the tasks involved in cassava processing while men increase their labour input in cassava producing areas where cassava is mainly produced for cash and for urban consumers. COSCA study (1996) showed that in $76.0 \%$ of the villages selected in six African countries, processing was carried out by women.

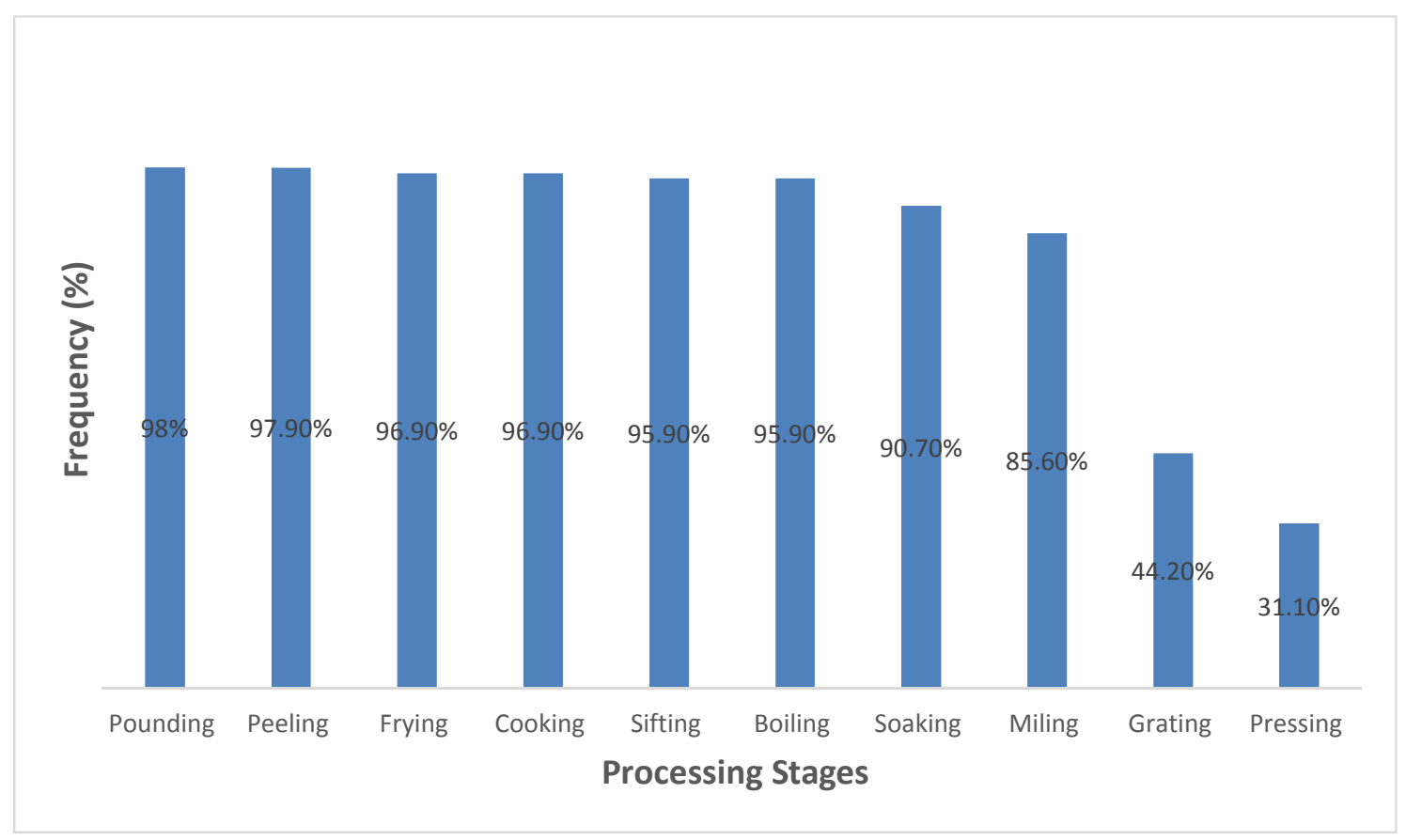

Fig. 3: Bar chart showing the roles performed by women in cassava processing

Pounding is a way of preparing fine, smooth and soft mash from fermented cassava tubers using mortar and pestle. It is usually a strenuous activity as it is still done manually in most Africa families where cassava is consumed. Women and children often perform this task as it is most times seen as cooking but men get involved especially when it is for the market. The indication of pounding as the most performed activity by women in the area is in line with the preference for $\mathrm{f} u f u$ as the most available cassava product.

Peeling involves the removal of the outer covering of cassava tubers. Tubers are often subjected to this stage after harvesting. However, when the tubers are used for fufu production, this activity may be skipped but must be thoroughly washed to avoid interference with the colour of the product. Peeling is still done manually in most African societies by children and women. Frying involves constant heating of the sundried/pressed cassava with constant stirring in wide, shallow, non-sticky metal pans till it becomes light or crisp garri. During the process of heating, red oil may or may not be added which prevents the burning of the garri during the process of heating and gives light yellow colour to the finished product, thus yielding yellow or white garri. This may be time consuming as it is done bit by bit. Soaking is synonymous with fufu preparation. It involves the peeling, washing and cutting of cassava tubers and putting them in containers filled with water to stay for some days to ferment after which it is sieved. Grating and pressing are very tedious and mostly done by men. Grating could be 
done manually or mechanically. However, in recent times, it is done mechanically whereby people take their tubers to the mills for grating. Pressing is also being done mechanically in recent times. However, some farmers still employ the local method of tying with sticks to promote dehydration. In some places, heavy stones are used for the pressing in which case they are placed on the pulp contained in a bag and allowed to last for some days. This is usually done by men due to its strenuous nature.

\section{Constraints to cassava processing}

Table 2 indicates that unstable power supply $(\bar{X}=3.4)$, inadequate poor supply $(\bar{X}=3.3)$, length of time involved $(\bar{X}=3.0)$, lack of storage facilities $(\bar{X}=3.4)$, poor government policies $(\bar{X}=3.3)$, inadequate information on processing of cassava products $(\bar{X}=3.3)$, lack of sophisticated equipment $(\bar{X}=3.1)$, high physical energy requirement $(\bar{X}=2.8)$ and poor extension coverage $(\bar{X}=2.8)$ were the constraints faced by the women farmers in cassava processing. These could affect the quantity of cassava produced thus adversely affecting food security and poverty reduction. Unstable power supply (electricity) could compel farmers into looking for alternative sources of energy for processing which may be costly and unsustainable. For, example resorting to the use of charcoal or fuelwood could have some environmental costs such as deforestation and climate change.

Several studies have reported the need for credit among rural farmers in Africa (Bolarinwa \& Oyeyinka, 2005; Ekwere \& Edem, 2014; Olagunju \& Adeyemo, 2008) and this is more among women farmers whose access to credit is limited by socio-cultural norms. Inadequate capital could prevent investments in cassava processing such as the ownership of mechanical graters, frying pans etc. even the access to other sources of energy apart from electricity. Lack of storage facilities may reduce the quantity of cassava processed since unprocessed products face the risk of spoilage. Lack of sophisticated equipment could lead to drudgery in cassava processing and may increase wastage of cassava products. Poor extension coverage could lead to poor access to information on processing. Mogues et al. (2009) reported a relatively lower access to extension service among women farmers in Ethiopia. These findings concur with a report by Ogunleye et al. (2008) and Muhammad-Lawal et al. (2013) which identified these factors as constraints to cassava processing in Nigeria.

Table 2: Distribution of respondents according to constraints in cassava processing

\begin{tabular}{llc}
\hline Constraints & $\mathbf{X}$ & S.D \\
\hline Inadequate finance & $3.29^{*}$ & 0.2947 \\
High cost of labour & 2.34 & 0.2249 \\
Inadequate transport facilities & $3.09^{*}$ & 0.1850 \\
Unstable power supply & $3.44^{*}$ & 0.2390 \\
Lack of sophisticated equipment & $3.06^{*}$ & 0.1794 \\
Lack of storage facilities & $3.40^{*}$ & 0.2343 \\
Poor government policies & $3.26^{*}$ & 0.2121 \\
Poor market demand for processed products & 2.20 & 0.2038 \\
Poor access to market information & $2.79^{*}$ & 0.1260 \\
Lack of rural feeder roads & 2.20 & 0.0121 \\
Inadequate information on processing & $3.33^{*}$ & 0.2234 \\
Fluctuations in weather & 2.54 & 0.0100 \\
Manual processing takes time & $3.41^{*}$ & 0.0247 \\
High physical energy requirement & $2.79^{*}$ & 0.0127 \\
Dominance of men in decision & 2.09 & 0.0140 \\
Poor extension coverage & $2.78^{*}$ & 0.0126 \\
Long period of time spent on processing & $3.00^{*}$ & 0.0172 \\
Price instability & $3.34^{*}$ & 0.2249 \\
\hline
\end{tabular}

Source: Field Survey Data, 2015 


\section{Conclusion and Recommendations}

Cassava is an important staple and is transforming into an important cash crop in Nigeria. It is available in such products as garri, fufu and cassava balls. Urban women play actively roles in cassava processing. However, its processing is constrained by a lot of factors such as unstable power supply, inadequate finance, length of time involved and lack of storage facilities. Until, these constraints are adequately addressed, the potentials of cassava as a food security crop will remain largely untapped in urban areas in Nigeria. In order to avoid that, the following recommendations are therefore made:

1. Loans should be made available to farmers by the government and other relevant agencies. This could be achieved through the revival of the moribund agricultural banks and encouraging farmers to belong to cooperative societies for easy access to the loans.

2. Farmers should be provided with modern cassava processing equipment such as pressing machine and grating machine at subsidized rates by the government and other development agencies. This can also be achieved through the formation of cooperative societies to enable farmers pool their resources and potentials together.

3.The agricultural extension agencies should organize capacity building programmes on cassava processing for farmers to enhance their capability in cassava processing.

\section{References}

Agbamu, J.U., 2004. Essentials of agricultural communication in Nigeria. Lagos: Malthouse Press, P. 203.

Ani, A.O., 2004. Women in agriculture and rural development. Maiduigiri: Priscaqiulla Publishers.

Bello, M., E.P. Ejembi, E. Allu and T.A.K. Anzaku, 2013. Rural women processing cassava in Doma local government area of Central Nigeria deserve technical attention. Research on Humanities and Social Sciences, 2(1), $11-20$.

Bolarinwa, K.K. and R.A. Oyeyinka, 2005. Communal conflict impact on agricultural extension agents' operation in Atisbo local government area of Oyo State, Nigeria. Journal of Agricultural Extension, 8(1).

Chekene, M.B., 2015. Factors influencing the adoption of improved rice varieties in Borno State, Nigeria. Journal of Agricultural Extension, 19(2), 21 -34.

Collaborative Study of Cassava in Africa, 1996. Working Paper, 13, COSCA.

Echebiri, R.N. and M.E.H. Edaba, 2008. Production and utilization of cassava in Nigeria: prospects for food security and infant nutrition. PAT, 4(1): $38-52$.

Ekwere, G.E. and I.D. Edem, 2014. Evaluation of agricultural credit facility in agricultural production and rural development. Global Journal of Human Social Science, Geography, Geo-Sciences, Environmental Disaster Management, 14(3): $19-26$.

Food and Agricultural Organization (FAO), 2004. The global cassava development strategy and implementation plan. Proceedings of the validation forum on the global cassava development strategy. FAO, Rome.

Food and Agricultural Organization (FAO), 2011. The role of women in agriculture. Prepared by the SOFA Team and Cheryl Doss. ESA Working Paper No. $11-02$. Retrieved online on $24^{\text {th }}$ February, 2016 from http://www.fao.org/economic/esa.

Food and Agricultural Organization Statistics, 2013. FAOSTAT database of crop statistics. FAO, Rome.

Food and Agricultural Organization, 2011. Gender differences in assets. ESA working paper No. 11 12. Agricultural Development Division, FAO.

Food and Agriculture Organization, FAO, 2013. Save and grow: Cassava. A guide to sustainable production intensification. FAO, Rome.

Food and Agriculture Organization, 2013. Save and grow: Cassava. A guide to sustainable production intensification. FAO, Rome, Italy.

Food and Agriculture Organization, 2017. Food outlook: biannual report on global food market. FAO. Rome, Italy.

Imo state. (n.d). Retrieved online from http://en.m.wikipedia.org/wiki.imo_(state). 
International Food Information Council Foundation (IFICF), 2010. What is a processed food? You might be surprised understanding our food communication tool kit. Information handout for the IFCIF.

International Fund for Agricultural Development (IFAD) \& Food and Agricultural Organization (FAO), 2000. The world cassava economy: facts and outlook.

James, D. and T. Faleye, (2015). Cassava mechanization prospects and future in Nigeria. International Research Journal of Agricultural Science and Soil Science, 5(3), 98 - 102.

Mogues, T., Cohen, M.J., Birner, R., Lemma, M. Randriamamonjy, J. F. Tadesse and Z. Paulos, 2009. Access and governance of rural services: Agricultural extension and drinking water supply in Ethiopia. Ethiopia Strategy Support Programme II (ESSP- II). International Food Policy Research Institute (IFPRI).

Muhammad-Lawal, A., O.A. Ometosho and F.A. Oyedemi, 2013. An assessment of the economics of cassava processing in Kwara state, Nigeria. Invited paper presented at the $4^{\text {th }}$ International Conference of the Association of Agricultural Economists, September 22 - 25, Hammamet, Tunisia.

Naziri, D., Quaye, W., B. Siwoku, S. Wanlapatit, V.P. Tu and B. Bennet, 2014. Not all those who wander are lost: a comparative analysis of postharvest losses in cassava value chains in Ghana, Nigeria, Thailand and Vietnam. Paper submitted for the $14^{\text {th }}$ Congress of the European Association of Agricultural Economists. "Agri-food and Rural Innovations for Healthier Societies", Ljubi Jana, Slovenia.

Nweke, F.I., D.S.C. Spencer and J.K. Lynam, 2002. The cassava transformation: Africa's best-kept secret. East Lansing, USA. Michigan State, University Press.

Nyirenda, D.B., L. Chiwona-Karltun, M. Chitundu, S. Haggblade and L. Brimer, 2011. Chemical safety of cassava products in regions adopting cassava in regions adopting cassava production and processing - experience from Southern Africa. Food and Chemical Toxicology, 49, 607 - 612.

Ogunleye, K.Y., R.G. Adeola and I.O. Ibigbami, 2008. Gender roles in cassava processing activities among processors in Ogo-Oluwa local government area of Oyo state, Nigeria. International Journal of Agricultural Economics and Rural Development, 1(1): 30 - 37.

Okoroafor, K.M. and C.U. Nwaobiala, 2014. Effectiveness of cassava women processors in value addition technologies in Abia State, Nigeria. International Journal of Agricultural Science, Research and Technologyin Extension and Education Systems, 4(3), 137 - 142.

Olagunju, F.I. and R. Adeyemo, 2008. Evaluation of operational performance of the Nigerian Agricultural Credit Cooperative and Rural Development Bank (NACRDB) in Southwestern Nigeria. IJAERD Press.

Oluwatosin, F.M., 2011. Measuring technical efficiency of yam farmers in Nigeria: a stochastic parametric approach. Agricultural Journals, 6(2): 40-46.

Onyemauwa, C.S., 2010. Analysis of household consumption of cassava products in Ohaozara, Ebonyi State, Southeast Nigeria. Researcher, 2(6): 1-6.

Onyemauwa, C.S., 2012. Analysis of women participation in cassava production and processing in Imo State, Nigeria. Journal of Economics and Sustainable, 3(5): 81 - 90.

Presidential Initiative on Cassava, 2006. Cassava master plan: a strategic action plan for the development of the Nigerian cassava industry.

Sanchez, T., D. Dufor, J.L. Moreno, I.J. Aragon, M. Dominguez and H. Ceballos, 2016. Changes in extended selflife of cassava roots during storage in ambient conditions. International Center for Tropical Agriculture (CIAT), Apartado, Cali, Colombia.

Van Boekel, M., V. Fogliano, N. Pellergrini, C. Stanton, G. Scholz, S. Laliljie, V. Somoza, D. Knorr, P.R. Jasti, and G. Eisenbrand, 2010. A review on the beneficial aspects of food processing. Molecular Nutrition and Food Research, 54, 1215 - 1247.

Westby, A., 2002. Cassava utilization, storage and small-scale processing. In: R.J. Hillocks, J.M., Thresh \& A.C. Belloti (Eds.), Cassava: Biology, production and utilization. 